\title{
Jubiläum und Abschied
}

Liebe Leserinnen, liebe Leser,

große Feiern sind in Zeiten von Covid 19 nicht angesagt. Doch 60 Jahre JOT dürfen nicht einfach so sang- und klanglos verstreichen. Daher erscheint diese Ausgabe von JOT mit einem Jubiläums-Sonderteil. 1960 erschien die erste Ausgabe von Schleifen und Polieren, die im Laufe der Jahrzehnte zuerst in Oberfläche, später in Oberfläche + JOT und schließlich in JOT umbenannt wurde. Vor zehn Jahren, zum 50. Jubiläum, gaben wir im Jubiläumsbeitrag einen umfassenden Rückblick auf Meilensteine der Entwicklung in der Oberflächentechnik. Für die jetzige Jubiläumsausgabe finde ich es passender, nach vorne zu blicken, vor allem um Neugierde zu wecken und auf die Herausforderungen der Zukunft hinzuweisen. Zur Inspiration möchte ich Ihnen die fünf Beiträge im Jubiläumsteil dieser Ausgabe besonders empfehlen. Die Beiträge zeigen eindrucksvoll, wohin sich die industrielle Oberflächentechnik entwickeln kann und wird. Nur so viel vorneweg: Die Zukunft der Oberflächentechnik bleibt spannend! Das JOT-Team freut sich darauf, die Branche wie bereits in den vergangenen 60 Jahren auch in Zukunft als Fachmedium zu begleiten - gleich ob gedruckt oder über verschiedene digitale Wege.

31 Jahre lang durfte ich die JOT mitgestalten, davon 28 Jahre als Chefredakteur. Mit dieser Ausgabe verabschiede ich mich nun in den Ruhestand. In unterschiedlichen Jobs war die Oberflächentechnik über 45 Jahre hinweg meine berufliche Heimat, in der ich die Entwicklung der industriellen Oberflächentechnik intensiv miterlebt habe. Es war eine tolle Zeit! Im Namen des JOT-Teams bedanke ich mich herzlich bei den Autoren, den Anzeigenkunden und bei Ihnen, liebe Leserinnen und Leser, für die jahrelange Treue. Mein besonderer Dank gilt dem gesamten JOT-Team, das immer an einem Strang gezogen hat und hinter mir stand.

Mit Holger Seybold übernimmt ein erfahrener und zukunftsorientierter Fachzeitschriften-Macher die JOT-Chefredaktion. Ihm und Ihnen allen viel Erfolg und alles Gute!

Ihr

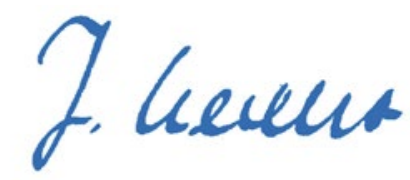

Jochen Kecht

Chefredakteur

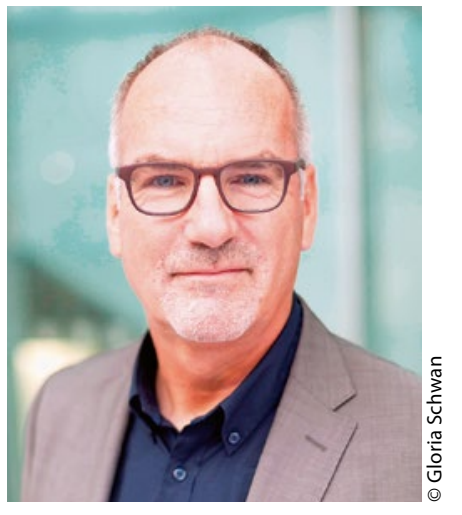

